\title{
Effects of isoimperatorin on proliferation and apoptosis of human gastric carcinoma cells
}

\author{
HAI-BO YANG ${ }^{1 *}$, HUI-RU GAO ${ }^{1 *}$, YUAN-JING REN ${ }^{1}$, FEI-XIANG FANG ${ }^{1}$, HONG-TAO TIAN $^{1}$, \\ ZHEN-JIANG GAO ${ }^{1}$, WEI SONG ${ }^{1}$, SHAO-MIN HUANG ${ }^{2}$ and AN-FANG ZHAO ${ }^{1}$ \\ ${ }^{1}$ Department of Biological Pharmacy, School of Life Science and Engineering, Henan University of Urban Construction, \\ Pingdingshan, Henan 467044; ${ }^{2}$ Department of Obstetrics and Gynecology, Center for Reproductive Medicine, \\ The First Affiliated Hospital of Xiamen University, Xiamen, Fujian 361004, P.R. China
}

Received February 21, 2017; Accepted October 26, 2017

DOI: $10.3892 / \mathrm{ol} .2018 .8303$

\begin{abstract}
Resistance to apoptosis is an characteristic of cancer cells that serves a critical function in tumor development and represents a target for antitumor therapy. Isoimperatorin (ISOIM), a coumarin compound, exhibits antitumor functions in multiple types of tumor cells. However, its antitumor effects and molecular mechanisms with respect to gastric cancer have not been elucidated. The present study assessed the anti-proliferative and apoptotic effects of ISOIM on human BGC-823 gastric cancer cells and elucidated its underlying molecular mechanisms. Cell proliferation was evaluated using MTT assays. Analysis of cell morphology was performed by hematoxylin and eosin, Hoechst 33258 and acridine orange/ethidium bromide staining. In addition, cell cycle and apoptosis was evaluated using flow cytometry analysis; expression of apoptosis-associated proteins was studied by western blotting. The results of the present study revealed that ISOIM significantly inhibited cell proliferation by arresting the cell cycle at the $\mathrm{G}_{2} / \mathrm{M}$ phase and induced apoptosis by increasing Bcl-2-associated X (Bax) expression with a concomitant decrease in Bcl-2 expression, resulting in a decreased Bcl-2/Bax ratio compared with the control. In addition, ISOIM treatment also resulted in cytochrome $c$ translocating from the mitochondria to the cytosol. Furthermore, caspase-3 was significantly activated in response to treatment with ISOIM, suggesting that apoptosis in BGC-823 cells is induced in the mitochondrial pathway. Taken together, the results of the present study indicate that ISOIM may significantly induce apoptosis in BGC-823 cells and that the pro-apoptotic mechanisms of ISOIM could be associated with the mitochondrial pathway.
\end{abstract}

Correspondence to: Dr An-Fang Zhao, Department of Biological Pharmacy, School of Life Science and Engineering, Henan University of Urban Construction, 7 Daxiangshan Road, Pingdingshan, Henan 467044, P.R. China

E-mail: zhaoanfang001@126.com

*Contributed equally

Key words: isoimperatorin, apoptosis, mitochondrial pathway

\section{Introduction}

Apoptosis serves an important function in the normal development and stability of organisms (1). Apoptosis imbalance is associated with numerous diseases, including developmental defects, autoimmune diseases, neurodegenerative disorders and, in particular, tumor occurrence, development and metastasis (2). Research on inducing tumor cell apoptosis has become a field of interest in cell biology and the biomedical sciences. The aim of current research on tumor cell apoptosis is to develop safer and more effective therapeutic agents for treating tumors. Isoimperatorin (ISOIM) belongs to the 6,7-furan coumarin family of compounds and is the major effective component in the umbelliferae family, which includes Angelica dahurica, Heracleum, coastal glehnia root, Chinese angelica and Peucedanum ostruthium, and is commonly used in traditional Chinese medicine (3). ISOIM is a secondary plant metabolite that possesses multiple pharmacological properties, including analgesic, antiviral, antitumor, anti-inflammatory, antibacterial and anti-hypertensive properties (4-8). ISOIM may inhibit numerous types of human tumor cell from proliferating, including lung cancer A549, ovarian cancer SK-OV-3, skin cancer SK-MEL-2, glioblastoma XF498, HCT-15 colon cancer and MCF-7 breast cancer cells (4-9). A previous study reported that ISOIM may inhibit SGC-7901 cells from proliferating and alter the expression levels of pro-apoptotic and anti-apoptotic proteins (10). However, the present study has certain limitations, including assessing too few cell lines, not observing cell morphology or detecting the cell cycle.

Therefore, the present study used the stomach cancer BGC-823 cell line as an in vitro model to confirm the effects of ISOIM, assess changes in apoptosis-associated proteins in the B-cell lymphoma 2 (Bcl-2) and caspase-3 families in ISOIMtreated cells and to determine the molecular mechanism of ISOIM-induced BGC-823 cell apoptosis.

\section{Materials and methods}

Reagents. ISOIM was obtained from Shanghai Aladdin Bio-Chem Technology Co., Ltd. (Shanghai, China), maintained in $100 \mathrm{mM}$ stock solutions in ethanol and stored at $-20^{\circ} \mathrm{C}$. The stock solutions were colorless to inhibit them from 
influencing the results of MTT, flow cytometry (FCM) and acridine orange (AO)/ethidium bromide (EB) staining (3). MTT, bisbenzimide (Hoechst 33258), AO, EB and propidium iodide (PI) were purchased from Sigma-Aldrich; Merck KGaA (Darmstadt, Germany). RPMI-1640 medium and 100\% fetal bovine serum were purchased from Gibco; Thermo Fisher Scientific, Inc. (Waltham, MA, USA). Mouse monoclonal antibodies against human caspase-3 (cat. no. sc7272; 1:200), Bcl-2-associated X (cat. no. sc-4239; 1:200), Bcl-2 (cat. no. sc509; 1:200), cytochrome $c$ (cat. no. sc13561; 1:200), cyclin D1 (cat. no. sc4074; 1:500), cyclin dependent kinase 1 (cat. no. sc-53219; 1:500), cyclin B1 (cat. no. sc-4073; 1:300) and p21 (cat. no. sc-6246; 1:500) were obtained from Santa Cruz Biotechnology, Inc. (Dallas, TX, USA). Furthermore, horseradish peroxidase conjugated rabbit anti-Mouse IgG antibody (A9044, Sigma) were also used at room temperature for $1 \mathrm{~h}$ and detected using an enhanced chemiluminescence system (Pierce; Thermo Fisher Scientific, Inc.). All other reagents and solvents used were of analytical grade.

Cell culture and induction of ISOIM. BGC823, HGC-27 and MGC-803 human gastric cancer cells were obtained from the Shanghai Institute of Biochemistry and Cell Biology (Shanghai, China). The BGC823, HGC-27 and MGC-803 cells were cultured in RPMI-1640 medium with $10 \%$ fetal bovine serum (Gibco; Thermo Fisher Scientific, Inc.) and 5\% $\mathrm{CO}_{2}$ at $37^{\circ} \mathrm{C}$ for $48 \mathrm{~h}$. Cells were treated with RPMI-1640 medium (Gibco; Thermo Fisher Scientific, Inc.) containing various concentrations $(0.025,0.05,0.10,0.15$ and $0.2 \mathrm{mM})$ of ISOIM $24 \mathrm{~h}$ after seeding.

MTT assay. BGC-823 human gastric cancer cells were seeded on a 96 -well plate $\left(1 \times 10^{5} / \mathrm{ml}\right)$. Following incubation for $24 \mathrm{~h}$, cells were treated with multiple concentrations of ISOIM $(0.025,0.05,0.10,0.15$ and $0.2 \mathrm{mM})$ for $48 \mathrm{~h}$. Subsequently, the medium was discarded and $20 \mu \mathrm{l}$ MTT $(5 \mathrm{mg} / \mathrm{ml})$ was added to each well. Cells were incubated for $4 \mathrm{~h}$ at $37^{\circ} \mathrm{C}$, after which the medium was replaced with $150 \mu 1$ dimethyl sulfoxide. The optical density was measured using a microplate reader (Enspire; PerkinElmer, Inc., Waltham, MA, USA) at $490 \mathrm{~nm}$.

Hematoxylin and eosin $(H \& E)$ staining of BGC-823. $\mathrm{H} \& \mathrm{E}$ staining was performed as previously described (8); the treatment group cells were treated with $0.1 \mathrm{mM}$ ISOIM for $48 \mathrm{~h}$.

Hoechst 33258 and $A O / E B$ staining of $B G C-823$. After fixing with $100 \%$ methanol for $5 \mathrm{~min}$, cells were washed with PBS twice. BGC-823 cells seeded onto coverslips $\left(10^{5} / \mathrm{ml}\right)$ were stained with Hoechst 33258 for $10 \mathrm{~min}$ at room temperature and observed using a fluorescence microscope (magnification, $\mathrm{x} 400$ ). The treatment group cells were treated with $0.1 \mathrm{mM}$ ISOIM for $48 \mathrm{~h}$. For AO/EB staining, after washing with PBS three times, the control and treated groups were stained with $\mathrm{AO} / \mathrm{EB}$ staining solution $(10 \mu \mathrm{g} / \mathrm{ml})$ at room temperature for $3 \mathrm{~min}$ and observed using a fluorescence microscope (magnification, x200).

FCM analysis the cell cycle of BGC-823. FCM assays were performed as previously described (11). Treatment group cells were treated with $0.05,0.10$ or $0.15 \mathrm{mM}$ ISOIM for $48 \mathrm{~h}$.
FCM analysis for the cell apoptosis rate. BGC-823 cells were incubated in Annexin V-fluorescein isothiocyanate (Beyotime Institute of Biotechnology, Haimen, China) in darkness for $10 \mathrm{~min}$ at room temperature. Following centrifugation $(800 \mathrm{x} \mathrm{g}$ for $5 \mathrm{~min}$ at $4^{\circ} \mathrm{C}$ ) and cell resuspension in Annexin V-FITC binding buffer (Beyotime Institute of Biotechnology), cells were stained with 10\% PI staining solution (Beyotime Institute of Biotechnology) at room temperature. Following filtration with a 200-mesh sieve, cells were detected using flow cytometry. Treatment group cells were treated with $0.1 \mathrm{mM}$ ISOIM for $48 \mathrm{~h}$.

Western blot analysis. Western blot assays were performed as previously described (12). Treatment group cells were treated with $0.05,0.1$ and $0.15 \mathrm{mM}$ ISOIM for $48 \mathrm{~h}$ at $37^{\circ} \mathrm{C}$.

Statistical analysis. Statistical analysis was performed using SPSS software (version 19.0; SPSS, Inc., Chicago, IL, USA), including the calculation of half-maximal inhibitory concentration $\left(\mathrm{IC}_{50}\right)$. Data were represented as mean \pm standard deviation from at least 3 independent experiments. Student's t-test or one-way analysis of variance followed by by Bonferroni's test was used for comparison of 2 or $>2$ datasets, respectively. $\mathrm{P} \leq 0.05$ was considered to indicate a statistically significant difference.

\section{Results}

Anti-proliferative effects of ISOIM on BGC-823 cells. Since mitochondrial succinate dehydrogenase in living cells may reduce MTT to a bluish-purple, water-insoluble crystal, MTT is used to detect the number of viable cells and the proliferation of cells. In the present study, multiple gastric cancer cell lines were assessed, including BGC823 $\left(\mathrm{IC}_{50}=0.115 \mathrm{mM}\right)$, HGC-27 $\left(\mathrm{IC}_{50}=0.120 \mathrm{mM}\right)$ and MGC-803 $\left(\mathrm{IC}_{50}=0.146 \mathrm{mM}\right)$. The BGC- 823 cell line was the most sensitive to ISOIM of these cell lines and was therefore chosen for further study. ISOIM inhibited BGC-823 cell proliferation in a dose- and time-dependent manner (Fig. 1). The cytotoxic effect was increased in BGC-823 cells following increasing the concentrations of ISOIM $(0.025,0.05,0.10,0.15$ and $0.2 \mathrm{mM})$. The inhibition rate of cells treated with ISOIM for $48 \mathrm{~h}$ ranged between 7.69 and $74.92 \%$.

Cell shape changes in BGC-823 cells induced by ISOIM. Microscopic observation (Fig. 2) revealed that BGC-823 cells exhibited morphological changes in apoptotic cells following ISOIM treatment, including decreased size, cell membrane shrinkage, nuclear pyknosis, decreased numbers of nucleoli, highly condensed nuclear chromatin, budding and foaming from the cell membrane (Fig. 2B, D and F).

Following Hoechst 33258 staining, an uneven distribution, condensation and karyorrhexis of nuclear fluorescence appeared in BGC-823 cells treated with ISOIM (Fig. 2D). Following AO/EB staining, nuclear chromatin turned green; pyknotic shaped or round beads represented early apoptotic cells. Nuclear chromatin turned orange; pyknotic shaped or round beads represented late apoptotic cells. Numerous apoptotic cells were observed in BGC-823 cells treated with ISOIM (Fig. 2F). Control group cells were shown in Fig. 2A, C and E. 


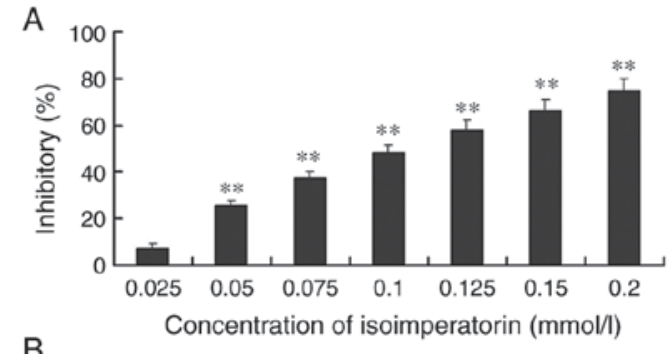

B

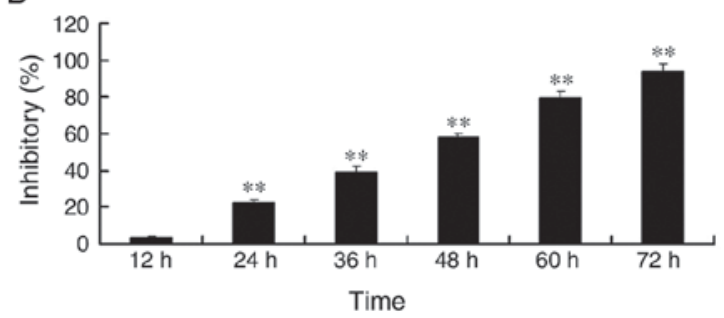

Figure 1. Cell inhibition rate changes dose- and time-dependently. (A) Exponentially proliferating BGC-823 cells were treated with different concentrations of ISOIM. (B) Exponentially proliferating BGC-823 cells were treated with $0.125 \mathrm{mM}$ ISOIM at different time periods. Cell growth inhibition was analyzed using the MTT assay. ${ }^{* *} \mathrm{P}<0.01$ vs. the control group. The control group is $0 \mathrm{mmol} / \mathrm{l}$ ISOIM and $0 \mathrm{~h}$ treatment time. ISOIM, isoimperatorin.

ISOIM-induced cell cycle changes in BGC-823 cells. To assess how ISOIM induced apoptosis in BGC-823 cells, FCM analysis was used to evaluate changes to the cell cycle distribution in BGC-823 cells induced by ISOIM. The results revealed that the number of ISOIM-treated cells in the $G_{2} / M$ phase was increased compared with that of the control group (from 18.49-46.96\%; Fig. 3A). The number of cells in the $S$ and $G_{0} / G_{1}$ phases decreased following treatment with ISOIM. The results indicated that ISOIM might be associated with induction of $\mathrm{G}_{2} / \mathrm{M}$ cell cycle arrest and subsequent apoptosis in BGC-823 cells. The expression of $\mathrm{G}_{2} / \mathrm{M}$ regulatory proteins, including cyclin $\mathrm{A} 1$, cyclin $\mathrm{B} 1$ and $\mathrm{CDK} 1$, was detected at different concentrations of ISOIM for $48 \mathrm{~h}$. The results demonstrated that the expression of mitosis-promoting factors, including cyclin A1, cyclin B1 and CDK1, was downregulated in treated cells compared with that in control cells (Fig. 3B).

Effect of cell apoptosis in BGC-823 cells induced by ISOIM. The cell apoptosis rate in cells treated with ISOIM was also assessed using FCM. The cell apoptosis rate reached $23.77 \%$ while the early apoptosis rate was $13.43 \%$ under $0.1 \mathrm{mM}$ ISOIM treatment (Fig. 4). The results of the present study confirmed the pro-apoptotic effect of ISOIM on BGC-823 cells.

Alterations in apoptosis regulatory proteins induced by ISOIM in BGC-823 cells. To further evaluate the potential mechanism of ISOIM-induced apoptosis, the present study analyzed the effect of ISOIM on the levels of apoptosis regulatory proteins using western blotting. The levels of cytochrome $c$ and caspase-3 increased following treatment with ISOIM compared with those of the untreated controls (Fig. 5), which induced a cascade of caspase activity $(\mathrm{P} \leq 0.01)$ that resulted in mitochondria-mediated apoptosis. Furthermore, the levels of Bax increased $(\mathrm{P} \leq 0.01)$ and the Bcl-2 levels decreased $(\mathrm{P} \leq 0.05)$, resulting in a decrease in the
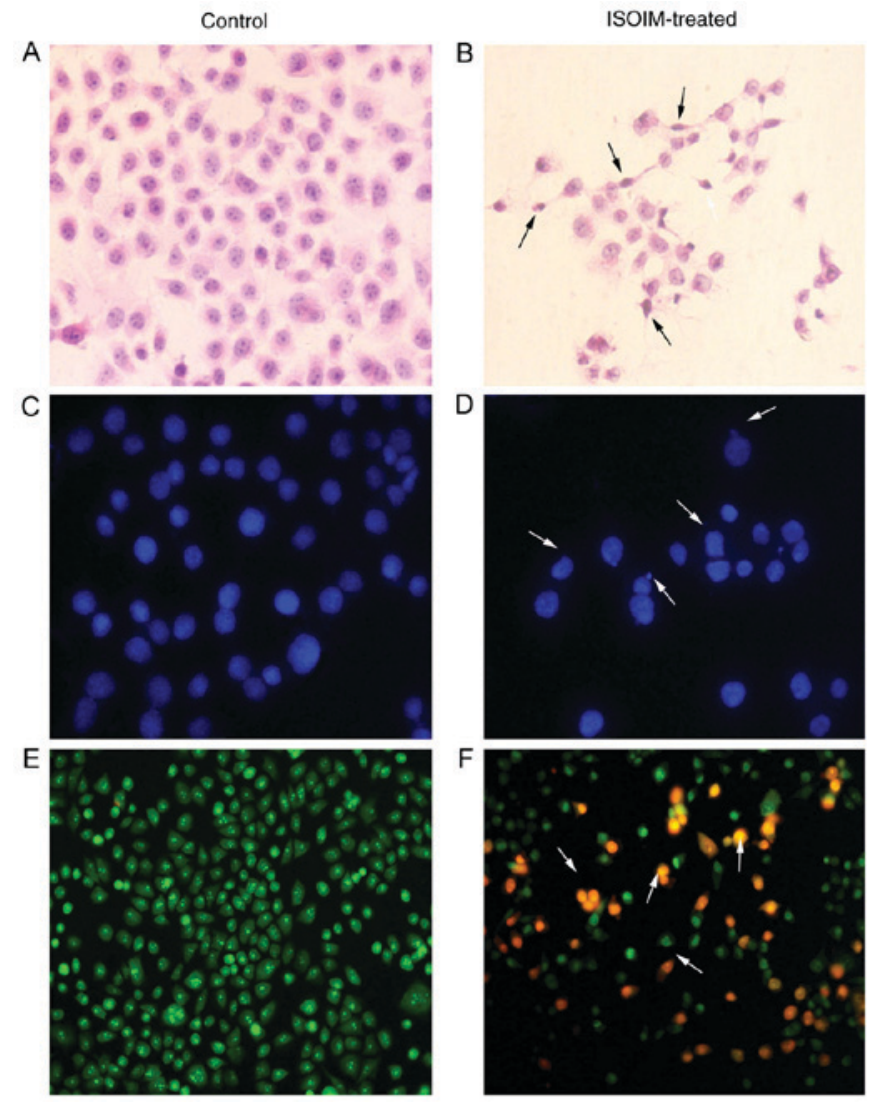

Figure 2. Morphological changes of BGC-823 cells following exposure to $0.1 \mathrm{mM}$ ISOIM for $48 \mathrm{~h}$. Morphological changes were visualized in the (A) control group and (B) ISOIM treatment group, using an inverted phasecontrast microscope with hematoxylin and eosin staining (magnification, $\mathrm{x} 400$ ). Morphological changes were visualized using a fluorescence microscope with Hoechst 33258 staining (magnification, $x 400$ ) in the (C) control group and (D) ISOIM treatment group. Morphological changes were visualized using a fluorescence microscope with acridine orange/ethidium bromide staining (magnification, x200) in the (E) control group and (F) ISOIM treatment group. Arrows indicate apoptosing cells. ISOIM, isoimperatorin.

anti-apoptotic/pro-apoptotic (Bcl-2/Bax) protein ratio prior to and following ISOIM treatment.

\section{Discussion}

Mitochondria serve a key function in the intrinsic apoptosis pathway (13-15). Previous studies have indicated that coumarin compounds induce apoptosis in cells via a mitochondria-dependent pathway (16-19). Consequently, the primary aim of the present study was to assess the potential mechanism by which ISOIM induces human BGC-823 gastric cancer cells to undergo apoptosis.

In the present study, the dose- and time-dependent proliferation inhibition of BGC-823 cells by ISOIM was demonstrated. Previous studies have revealed that ISOIM may induce apoptosis in multiple types of human malignant tumors $(9,20,21)$. The results of the present study indicated that, following treatment with $0.1 \mathrm{mM}$ ISOIM for $48 \mathrm{~h}$, a substantial degree of apoptosis in BGC-823 cells was detected. As a coumarin compound, the effects of ISOIM on BGC-823 cells corresponded to previous reports of the effects of other coumarin compounds on human breast cancer MCF7, human monocyte U937, mouse hepatocellular carcinoma Hepa-1, 

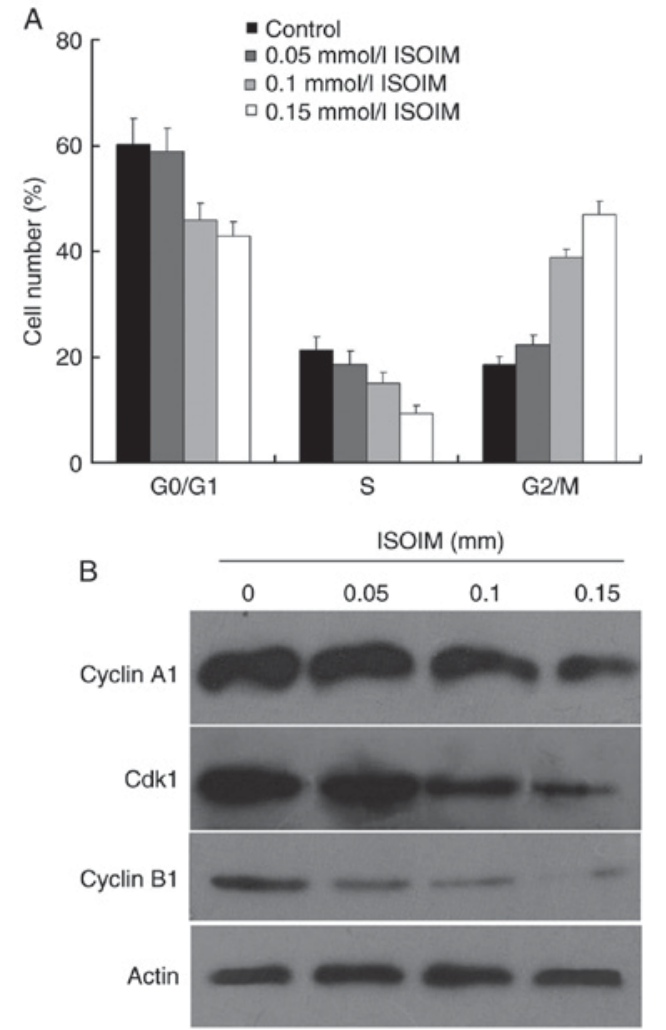

Figure 3. Effect of ISOIM on the BGC-823 cell cycle distribution. (A) Cell cycle analysis of BGC-823 cells using flow cytometry with propidium iodide staining and the corresponding DNA histograms. (B) The protein levels of cyclin A1, cyclin B1 and CDK1 were detected using western blot analysis. ISOIM, isoimperatorin; CDK1, cyclin dependent kinase 1.
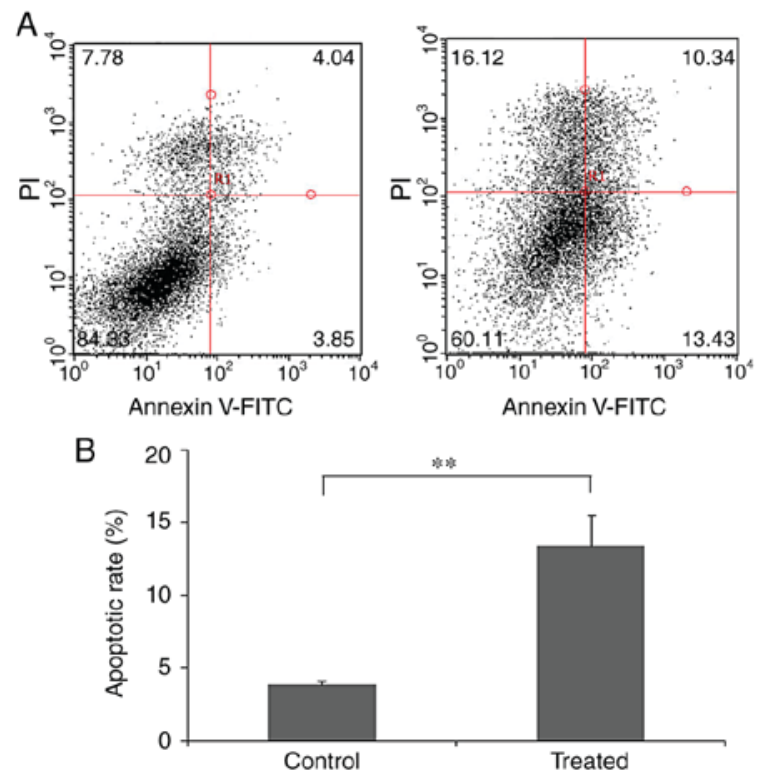

Figure 4. Effect of ISOIM on BGC-823 cell apoptosis. (A) Assessment of apoptosis using flow cytometry with Annexin V-FITC/propidium iodide staining and the corresponding dot-plot graph of BGC-823 cells. (B) Results of apoptosis rates following treatment with $0.1 \mathrm{mM}$ ISOIM for $48 \mathrm{~h} .{ }^{* *} \mathrm{P}<0.01$ vs. the control group. The control group is $0 \mathrm{mmol} / \mathrm{l}$ ISOIM. ISOIM, isoimperatorin; FITC, fluorescein isothiocyanate.

mouse adipocyte 3T3-L1, ovarian cancer, and human HL-60 and NALM-6 leukemia cells (14-16,22-25). The results of cell
A
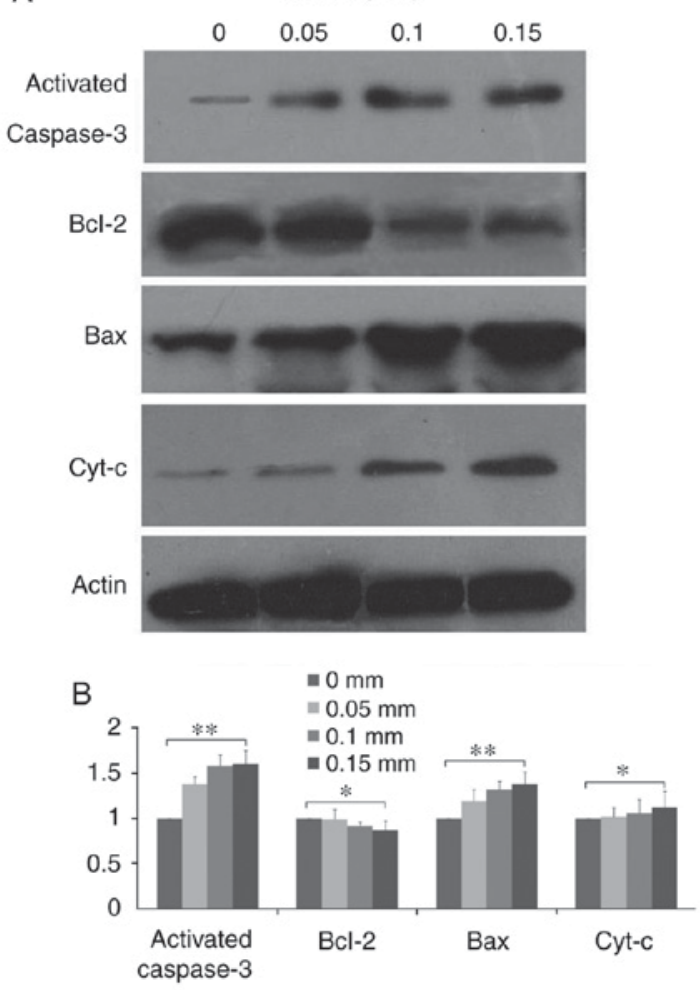

Figure 5. Apoptosis induced by ISOIM through the mitochondria-dependent pathway. (A) Expression of cytochrome $c$, caspase-3, Bcl-2 and Bax in BGC-823 cells treated with $0.05,0.10$ and $0.15 \mathrm{mM}$ ISOIM for $48 \mathrm{~h}$ (B) Results of apoptosis-associated proteins following treatment with different concentrations of ISOIM for $48 \mathrm{~h}$. ${ }^{*} \mathrm{P}<0.05$ and ${ }^{* *} \mathrm{P}<0.01$. Bcl-2, B-cell lymphoma 2; ISOIM, isoimperatorin; Bax, Bcl-2-associated X; Cyt- $c$, cytochrome $c$.

cycle analysis in the present study confirmed that ISOIM could significantly arrest the BGC-823 cell cycle at the $\mathrm{G}_{2} / \mathrm{M}$ phase and inhibit tumor cells from dividing, inducing apoptosis. The results of the present study on the cell cycle were consistent with the results of a prior study pertaining to the effects of other coumarin compounds on other types of tumor cell (17).

The Bcl-2 family are major regulators during the release of mitochondrial apoptotic factor (18). Bcl-2 functions in regulating mitochondrial permeability transition (pore opening and closing of apoptotic factors) is considered to be a primary regulator of apoptosis $(26,27)$. Bax functions by releasing cytochrome $c$, and that Bax transfers from the cytoplasm to the mitochondrial membrane under the stimulus of apoptotic signals and subsequently activates mitochondrially mediated apoptosis (28). $\mathrm{Bcl}-2$ is an anti-apoptotic protein that inhibits the promotion of apoptosis proteins on the mitochondrial membrane by forming oligomers that affect their anti-apoptotic functions (29). In addition, the caspase family functions crucially in mediating cell apoptosis (30). Caspase-3, which is downstream of the apoptosis cascade, is a crucial effector caspase and facilitates apoptosis; it serves as the main effector of apoptosis and the convergence point of apoptotic signaling (31). Activated caspase-3 indicates irreversible apoptosis (32). Therefore, the expression of caspase-3 reflects the level of apoptosis and the existence of an apoptosis promoter (33). To clarify whether ISOIM induces apoptosis in BGC-823 cells via the mitochondrial pathway, the present study evaluated the expression of $\mathrm{Bcl}-2$, Bax, caspase- 3 and 
cytochrome $c$ using western blotting. The results demonstrated that ISOIM downregulated the levels of Bcl-2 and upregulated the levels of cytochrome $c$, caspase- 3 and Bax. The results of the present study revealed that caspase- 3 was activated by ISOIM in a dose-dependent manner, and that ISOIM induced human gastric cancer cells to apoptosis. In vitro and in vivo analysis is a useful strategy for assessing anticancer drugs. The present study used in vitro analysis and demonstrated that ISOIM may induce apoptosis and its potential molecular mechanism; however, one deficiency of the present study is the lack of in vivo data, which should represent a future research direction in this field.

To conclude, the present study established that ISOIM, by activating pro- and anti-apoptotic genes, inhibits the cell cycle of BGC-823 gastric cancer cells at the $\mathrm{G}_{2} / \mathrm{M}$ transition, inhibits proliferation and induces the apoptosis of BGC-823 cells by initiating the activation of the mitochondrial pathway. Therefore, further assessing the mechanism of ISOIM, a anticancer compound, in inducing the apoptosis of human BGC-823 gastric cancer cells may be important in preventing this disease and anticancer research.

\section{Acknowledgements}

Not applicable.

\section{Funding}

This study was supported by the Henan Planning Project of Science and Technology (grant no. 132102310118).

\section{Availability of data and materials}

The datasets generated and analyzed in the present study are included in this published article.

\section{Authors' contributions}

HBY, HRG, YJR and FXF performed the experiments. HTT, ZJG, WS and SMH analyzed the data. AFZ designed the experiments and wrote the manuscript.

\section{Ethics and consent to participate}

Not applicable.

\section{Consent for publication}

Not applicable.

\section{Competing interests}

The authors confirm that they have no competing interests.

\section{References}

1. Kerr JF, Wyllie AH and Currie AR: Apoptosis: A basic biological phenomenon with wide-ranging implications in tissue kinetics. Br J Cancer 26, 239-257, 1972.

2. Jin Z and El-Deiry WS: Overview of cell death signaling pathways. Cancer Biol Ther 4: 139-163, 2005.
3. Wei Y and Ito Y: Preparative isolation of imperatorin, oxypeucedanin and isoimperatorin from traditional Chinese herb 'bai zhi' Angelica dahurica (Fisch. ex Hoffm) Benth. et Hook using multidimensional high-speed counter-current chromatography. J Chromatogr A 1115: 112-117, 2006.

4. Kim YK, Kim YS and Ryu SY: Antiproliferative effect of furanocoumarins from the root of Angelica dahurica on cultured human tumor cell lines. Phytother Res 21: 288-290, 2007.

5. Moon TC, Jin M, Son JK and Chang HW: The effects of isoimperatorin isolated from Angelicae dahuricae on cyclooxygenase-2 and 5-lipoxygenase in mouse bone marrow-derived mast cells. Arch Pharm Res 31: 210-215, 2008.

6. Kim DK, Lim JP, Yang JH, Eom DO, Eun JS and Leem KH: Acetylcholinesterase inhibitors from the roots of Angelica dahurica. Arch Pharm Res 25: 856-859, 2002.

7. Park HY, Kwon SB, Heo NK, Chun WJ, Kim MJ and Kwon YS: Constituents of the stem of Angelica gigas with rat lens aldose reductase inhibitory activity. J Korean Society Applied Biol Chem 54: 194-199, 2011.

8. Baek NI, Ahn EM, Kim HY and Park YD: Furanocoumarins from the root of Angelica dahurica. Arch Pharm Res 23: 467-470, 2000.

9. Kleiner HE, Reed MJ and DiGiovanni J: Naturally occurring coumarins inhibit human cytochromes P450 and block benzo[a]pyrene and 7,12-dimethylbenz[a]anthracene DNA adduct formation in MCF-7 cells. Chem Res Toxicol 16: 415-422, 2003.

10. Tong $\mathrm{K}$, Chang $\mathrm{X}$ and Chen $\mathrm{W}$ : Isoimperatorin induces apoptosis of the SGC-7901 human gastric cancer cell line via the mitochondria-mediated pathway. Oncol Lett 13: 518-524, 2017.

11. Yan S, Yuan L, Hong L, Jin L, Xiaohua S and Wenchang Z: 2,5-Hexanedione induces human ovarian granulosa cell apoptosis through Bcl-2, BAX, and CASPASE-3 signaling pathways. Arch Toxicol 86: 205-215, 2012.

12. Zhao X, Yang W, Shi C, Ma W, Liu J, Wang Y and Jiang G: The G1 phase arrest and apoptosis by intrinsic pathway induced by valproic acid inhibit proliferation of BGC-823 gastric carcinoma cells. Tumour Biol 32: 335-346, 2011.

13. Cohen GM: Caspases: The executioners of apoptosis. Biochem J 326: 1-16, 1997.

14. Reed JC: Cytochrome c: Can't live with it-can't live without it. Cell 91: 559-562, 1997.

15. Kroemer G and Reed JC: Mitochondrial control of cell death. Nat Med 6: 513-519, 2000.

16. Yang JY, Della-Fera MA and Baile CA: Esculetin induces mitochondria-mediated apoptosis in 3T3-L1 adipocytes. Apoptosis 11: 1371-1378, 2006.

17. Singh RK, Lange TS, Kim KK and Brard L: A coumarin derivative (RKS262) inhibits cell-cycle progression, causes pro-apoptotic signaling and cytotoxicity in ovarian cancer cells. Invest New Drugs 29: 63-72, 2011.

18. Adams JM and Cory S: The Bcl-2 protein family: Arbiters of cell survival. Science 281: 1322-1326, 1998.

19. Łazarenkow A, Nawrot-Modranka J, Brzezińska E, Krajewska U and Różalski M: Synthesis, preliminary cytotoxicity evaluation of new 3-formylchromone hydrazones and phosphorohydrazone derivatives of coumarin and chromone. Med Chem Res 21: 1861-1868, 2012.

20. Marumoto S and Miyazawa M: Beta-secretase inhibitory effects of furanocoumarins from the root of Angelica dahurica. Phytother Res 24: 510-513, 2010.

21. Kang SY and Kim YC: Neuroprotective coumarins from the root of Angelica gigas: Structure-activity relationships. Arch Pharm Res 30: 1368-1373, 2007.

22. Okuyama T, Takata M, Nishino H, Nishino A, Takayasu J and Iwashima A: Studies on the antitumor-promoting activity of naturally occurring substances. II. Inhibition of tumor-promoter-enhanced phospholipid metabolism by umbelliferous materials. Chem Pharm Bull (Tokyo) 38: 1084-1086, 1990.

23. Kleiner HE, Vulimiri SV, Reed MJ, Uberecken A and DiGiovanni J: Role of cytochrome P450 1a1 and 1b1 in the metabolic activation of 7,12-dimethylbenz[a]anthracene and the effects of naturally occurring furanocoumarins on skin tumor initiation. Chem Res Toxicol 15: 226-235, 2002.

24. Yang PY, Rui YC, Li K, Huang XH, Jiang JM and Yu L: Expression of intercellular adhesion molecule-1 in U937 foam cells and inhibitory effect of imperatorin. Acta Pharmacol Sin 23: 327-330, 2002 
25. Kleiner HE, Vulimiri SV, Miller L, Johnson WH Jr, Whitman CP and DiGiovanni J: Oral administration of naturally occurring coumarins leads to altered phase I and II enzyme activities and reduced DNA adduct formation by polycyclic aromatic hydrocarbons in various tissues of SENCAR mice. Carcinogenesis 22: 73-82, 2001.

26. Green DR and Kroemer G: The pathophysiology of mitochondrial cell death. Science 305: 626-629, 2004.

27. Chen Q and Lesnefsky EJ: Blockade of electron transport during ischemia preserves bcl-2 and inhibits opening of the mitochondrial permeability transition pore. FEBS Lett 585: 921-926, 2011

28. Jurgensmeier JM, Xie Z, Deveraux Q, Ellerby L, Bredesen D and Reed JC: Bax directly induces release of cytochrome $\mathrm{c}$ from isolated mitochondria. Proc Natl Acad Sci USA 95: 4997-5002, 1998.
29. Merino D and Bouillet P: The Bcl-2 family in autoimmune and degenerative disorders. Apoptosis 14: 570-583, 2009.

30. Zhivotovsky B: Caspases: The enzymes of death. Essays Biochem 39: 25-40, 2003.

31. Lakhani SA, Masud A, Kuida K, Porter GA Jr, Booth CJ, Mehal WZ, Inayat I and Flavell RA: Caspases 3 and 7: Key mediators of mitochondrial events of apoptosis. Science 311: 847-851, 2006

32. Nobuhiro M, Keiko N, Hiromi T, Takehiko S and Yukuto Y: An endoplasmic reticulum stress-specific caspase cascade in apoptosis. Cytochrome c-independent activation of caspase- 9 by caspase-12. J Biol Chem 277: 34287-34294, 2002.

33. Porter AG and Janicke RU: Emerging roles of caspase-3 in apoptosis. Cell Death Differ 6: 99-104, 1999. 